\title{
Ultra wideband coplanar waveguide fed spiral antenna for humanitarian demining
}

Thaysen, Jesper; Jakobsen, Kaj Bjarne; Appel-Hansen, Jørgen

Published in:

Proceedings of 30th European Microwave Conference

Link to article, DOI:

10.1109/EUMA.2000.338738

Publication date:

2000

Document Version

Publisher's PDF, also known as Version of record

Link back to DTU Orbit

Citation (APA):

Thaysen, J., Jakobsen, K. B., \& Appel-Hansen, J. (2000). Ultra wideband coplanar waveguide fed spiral antenna for humanitarian demining. In Proceedings of 30th European Microwave Conference (pp. 1-4). IEEE.

https://doi.org/10.1109/EUMA.2000.338738

\section{General rights}

Copyright and moral rights for the publications made accessible in the public portal are retained by the authors and/or other copyright owners and it is a condition of accessing publications that users recognise and abide by the legal requirements associated with these rights.

- Users may download and print one copy of any publication from the public portal for the purpose of private study or research

- You may not further distribute the material or use it for any profit-making activity or commercial gain

- You may freely distribute the URL identifying the publication in the public portal

If you believe that this document breaches copyright please contact us providing details, and we will remove access to the work immediately and investigate your claim. 


\title{
Ultra wideband coplanar waveguide fed spiral antenna for humanitarian demining
}

\author{
Jesper Thaysen $^{\mathrm{a}}$, Kaj B. Jakobsen ${ }^{\mathrm{a}}$, and Jørgen Appel-Hansen ${ }^{\mathrm{b}}$ \\ Technical University of Denmark \\ ${ }^{\mathrm{a}}$ Department of Applied Electronics, ${ }^{\mathrm{b}}$ Department of Electromagnetic Systems \\ jt@iae.dtu.dk kbj@iae.dtu.dk jaha.emi.dtu.dk
}

\begin{abstract}
A cavity backed coplanar waveguide to coplanar strip fed logarithmic uniplanar spiral antenna, which covers a 9 to 1 bandwidth with a return loss better than $10 \mathrm{~dB}$ from 0.4 to $3.8 \mathrm{GHz}$ is presented. A wideband balun covering the frequency range of the antenna was developed.

The constructed spiral antenna is very useful in a stepped frequency ground penetrating radar for humanitarian demining due to the very wide bandwidth, relatively small size, and being uniplanar. Successful detection of a small $5.4 \mathrm{~cm}$ non-metallic AP-mines in a pseudo minefield are presented.
\end{abstract}

\section{INTRODUCTION}

More than 120 million anti-personal (AP) mines have been laid around the world, killing or maiming innocent civilians every day. A large fraction of the AP-mines is similar to the minimum metal mine as the M56 APmines that are made almost entirely of plastic and explosive [1].

AP-mines are usually placed close to the surface (especially the smaller ones), but might be located as deep as 20-30 $\mathrm{cm}$ down and may be displaced from their original position as a consequence of natural events such as floods or drifting sands.

The maximum penetration depth for the GPR relates to the maximum depth at which a buried target can be detected, and depth resolution is the minimum discernible separation in the depth between two buried targets. The electromagnetic properties of ground materials strongly influence these performance characteristics.

To penetrate the ground effectively, lower frequency signals are required since the penetration decreases with frequencies. However, if the structures in the ground to be imaged are relatively close together, a broadband signal with good resolving power is required.

The metallic content in the AP-mines is often so small that the use of a metal detector is not feasible, thus the need for more efficient and affordable demining technologies and sensor systems is obvious.

The objective is to identify small mine-shaped nonmetallic objects buried in the ground using a stepped frequency ground penetrating radar (SF-GPR) [2].

Promising results from measurements on a large-scale in-door test field using the spiral antenna including the feed network with a SF-GPR is presented. The experiments are based on the SF-GPR approach, due to its advantages of measuring both the amplitude and phase information of the SF-GPR signal. This approach makes it possible to perform advanced signal processing.

\section{SELECTION OF THE ANTENNA TYPE}

For frequency-domain or time-domain techniques, the wider the frequency range, the better the range resolution is. Thus the use of a broadband antenna is essential for the signal and image processing in order to improve the detection of non-metallic AP-mines. Due to the signal processing, it is desirable to have as small sidelobes as possible.

The operation frequency range of the antenna for the SF-GPR is from 0.4 to $3.8 \mathrm{GHz}$ which yields a bandwidth of $3.4 \mathrm{GHz}$ corresponding to a radar range resolution of about $40 \mathrm{~mm}$ in soil. The lowest operation frequency of $0.4 \mathrm{GHz}$ is a compromise between the ground attenuation and the antenna size, whereas the feeding network limits the highest frequency.

Although a linearly polarised log-periodic antenna has a wide bandwidth and was an attractive candidate, circular polarisation is preferred to linear polarisation for the following reasons: if a linearly polarised antenna is used, the strength of the reflected wave from an object will depend on the azimuthal position of the antenna relative to the object. Also, if the orientation of the transmitting and receiving antennas is orthogonally to reduce the mutual coupling between the two linearly polarised antennas, then the receiving antenna will hardly detect the reflected wave from the object. Circular polarisation, however, does not have such problems; thus selections were narrowed down to spiral antennas [3].

Another advantages of circular polarisation is that the reflected signal from the surface of the soil has the opposite sense of polarisation compared to the incident wave, due to the fact that the ratio between the permittivity of soil and air is larger than one. Thus the antenna does not receive the reflected wave from the surface. However the reflected wave from the AP-mine has the same sense as the incident wave due to the fact that the permittivity ratio between mine and soil is less than one. This means that the only received signal is the one reflected from an object having a relative permittivity lower than soil, e.g., the AP-mines.

Among the spiral antennas, the conical spiral antenna radiates unidirectionally [4]. This unidirectionality of 


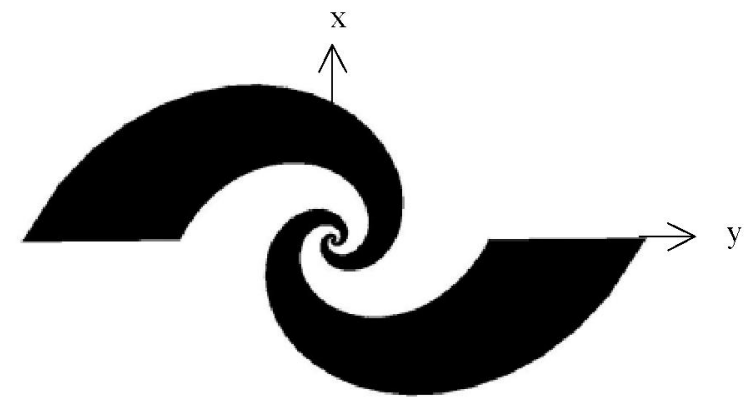

Figure 1. Illustration of the logarithmic spiral antenna with respect to rectangular $\mathrm{x}, \mathrm{y}, \mathrm{z}$ coordinates.

radiation is required for radar applications. However, for a conical spiral antenna, different frequency waves are radiated from different active regions of the cone. This gives rise to a problem for the range measurement, because the distance to the object depends on the frequency.

On the other hand, this problem is reduced with the logarithmic spiral antennas, because their shape is not conical but planar. However, the planar antennas have a bidirectional radiation property [5], [6]. By placing an absorbing material in a cavity the spiral antenna exhibits a unidirectional radiation pattern. The disadvantages are that only half of the input power is transformed into radiated power due to the presence of the absorber.

To aid the antenna design, the Electromagnetic Simulation Program, IE3D - a method of moment computer program - developed by Zeland Software [7], was used to predict the performance of the spiral antenna in terms of the radiation pattern and the input impedance. Furthermore the IE3D was used to predict the performance of the balun structure. The measured results of the constructed antenna and the balun structure were compared to the simulated results obtained from IE3D.

The FR-4 substrate is used for the antenna, which is commonly used for printed circuits. The FR-4 board is less expensive than commonly used microwave substrates such as, e.g., Duroid. This feature, combined with the advantages of the uniplanar circuit, makes this configuration suitable as a low-cost wideband antenna, which indeed is an advantage for a humanitarian SF-GPR.

\section{BALUN AND ANTENNA CONFIGURATIONS}

The logarithmic spiral shown in Figure 1 is a balanced antenna; thus a balun is required to transform the unbalanced coplanar waveguide (CPW) feed line to a balanced coplanar strip (CPS) feed line for the logarithmic spiral antenna. In [8] a CPW-to-CPS dipole antenna is presented, and a broadband CPW-to-CPS balun was investigated in [9]. In this paper the transition from CPW-to-CPS is accomplished by using a wideband balun, as in [10]. This balun is a modified version of that in [9] and has been used in [6] and [11].

The balun shown in Figure 2 includes a four section Chebyshev impedance transformer with a reflection coefficient of $\Gamma_{\mathrm{m}}=0.05$ which was designed in order to

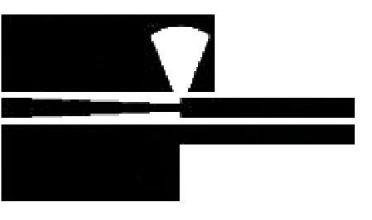

(a)

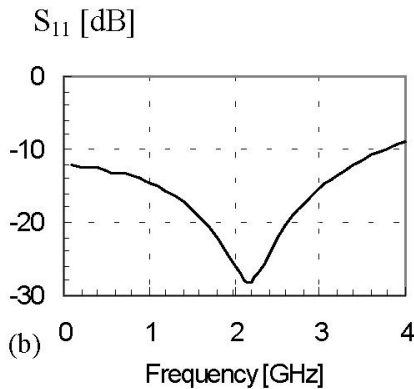

Frequency $[\mathrm{GHz}]$
Figure 2. The coplanar waveguide (CPW) to coplanar strip (CPS) balun (a). IE3D Simulation of the $\mathrm{S}_{11}$-parameter for the balun with the CPS terminated by an ideal $80 \Omega$ resistor.

change the impedance from $50 \Omega$ to $80 \Omega$ [10]. The input impedance of the spiral antenna is found to be approximately $80 \Omega$. The wideband transition from CPW-to-CPS is accomplished by using a slotted, radial patch. This patch represents a very wideband open circuit, which forces the field to be mainly between the two conductors of the coplanar strip feed line. Two bond wires near the discontinuity plane ensure that the potential on the two ground planes is equal [11]. The balun structure was fabricated on a small $16 \times 43 \mathrm{~mm}$ RT/Duroid substrate with a thickness of $0.785 \mathrm{~mm}$ and a relative dielectric constant $\varepsilon_{r}$ of 10.2 .

The logarithmic spiral antenna was designed using the equations, $r_{1}=r_{0} \mathrm{e}^{a \theta}$ and $r_{2}=r_{0} \mathrm{e}^{a\left(\theta-\theta_{0}\right)}$, where $r_{1}$ and $r_{2}$ are the outer and inner radii of the spirals, respectively; $r_{0}$ and $r_{0} \mathrm{e}^{-a \theta_{0}}$, are the initial outer and inner radii, respectively; $a$ is the growth rate, and $\theta$ is the angular position. To obtain the most frequency independent radiation pattern, and at the same time the most constant input impedance the dimensions are found to be $r_{0}=$ $2.1 \mathrm{~mm}, a=0.5 \mathrm{rad}^{-1}$, and $\theta_{0}=1.3 \mathrm{rad}=75^{\circ}[10]$.

The spiral antenna illustrated in Figure 1 consists of two equal arms each 1.5 turn. The spiral antenna is fabricated on a $220 \times 430 \mathrm{~mm}$ large FR-4 substrate with a thickness of $1.5 \mathrm{~mm}$ and a relative dielectric constant $\varepsilon_{r}$ of 4.4. The antenna is designed to meet conditions where circular polarisation is required; thus the minimum frequency is where the electrical length of the arm corresponds to one wavelength [5], [12]. This is the case for a frequency of $0.4 \mathrm{GHz}$.

\section{NUMERICAL AND EXPERIMENTAL RESULTS}

Simulations on the balun structure shown in Figure 2 (a) using IE3D, are performed by substituting the antenna with an ideal $80 \Omega$ resistor. In the frequency range from $100 \mathrm{kHz}$ to $3.85 \mathrm{GHz}$ the simulated return loss is better than $10 \mathrm{~dB}$, as shown in Figure 2 (b). The balun structure was fabricated and connected to the fabricated prototype of the spiral antenna to verify the performance. The reflection coefficient, $\mathrm{S}_{11}$, of the spiral antenna including the CPW-to-CPS feed network is determined using an HP $8720 \mathrm{D}$ and an HP8752A network analyser. The experimental results are shown in Figure 3 for the CPW-fed spiral antenna. The measured bandwidth, for a return loss better than $10 \mathrm{~dB}$ is from 0.4 


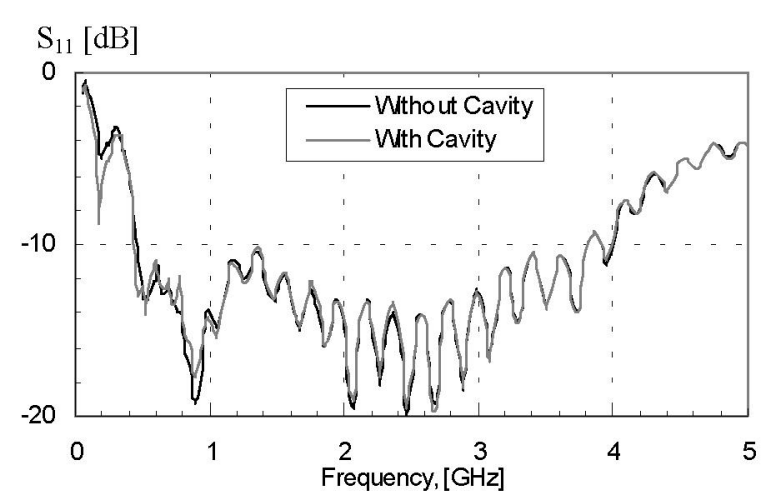

Figure 3. The measured $\mathrm{S}_{11}$-parameter for the CPW-fed spiral antenna placed on FR-4 substrate material with and without a cavity.

Mag. [dB]

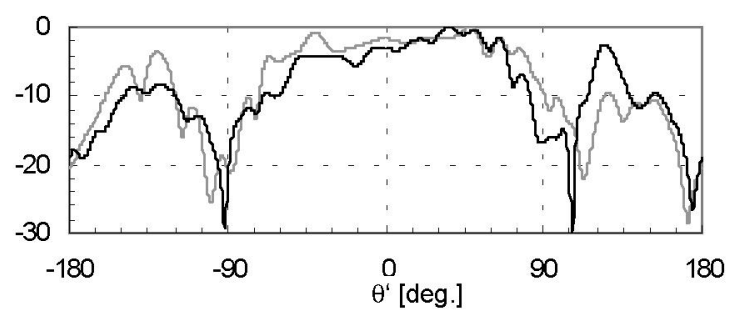

Figure 4. Measured $\theta$-cuts for $\phi_{0}=0^{\circ}$ (black) and for $\phi_{0}=90^{\circ}$ (grey). Positive values of $\theta^{\prime}$ corresponds to $\phi=\phi_{0}, \theta=\theta^{\prime}$ and negative value of $\theta$ 'corresponds to $\phi=\phi_{0}+180^{\circ}, \theta=-\theta^{\prime}$; with respect to the polar axis (z-axis) of the spiral antenna at $2.6 \mathrm{GHz}$.

to $3.8 \mathrm{GHz}$. The observed ripple on the measured reflection coefficient is due to a $0.4 \mathrm{~m}$ RG316U flexible coaxial cable that is connected to the CPW on the balun.

The simulated input impedance for the spiral antenna is $80 \mathrm{ohm}$, whereas the measured and the simulated impedances for the spiral antenna including the CPW-toCPS feed network is found to be matched to $50 \Omega$.

An absorbing material and polystyrene foam that has a thickness of $150 \mathrm{~mm}$ and $50 \mathrm{~mm}$, respectively, fill up the back of the constructed cavity [13]. In Figure 3 the measured $S_{11}$-parameter for the cavity backed spiral antenna can be compared to the measured $S_{11}$-parameter for the spiral antenna without a cavity. Hardly any difference is observed in the $S_{11}$-parameter for the spiral antenna with or without a cavity. This result indicates that there is a good reason to believe that the radiation in the main direction remains unchanged in the presence of the cavity.

Measurements in an anechoic environment in the Sperical Near-field Antenna Test Facility (SNATF) at the Technical University of Denmark are made in order to measure the far-field radiation pattern and to verify the simulated polarisation in the frequency range from $0.8 \mathrm{GHz}$ to $2.6 \mathrm{GHz}$ [14]. Figure 4 shows the radiation patterns of the cavity backed spiral antenna at a frequency of $2.6 \mathrm{GHz}$. The radiation in the $\theta=180^{\circ}$ direction is $20 \mathrm{~dB}$ lower due to the absorbing material.

The directivity is estimated to $6.6 \mathrm{~dB}$ and $2.7 \mathrm{~dB}$ at $0.8 \mathrm{GHz}$ and $2.6 \mathrm{GHz}$, respectively, by using the measured half-power beamwidth $(H P B W)$. From the

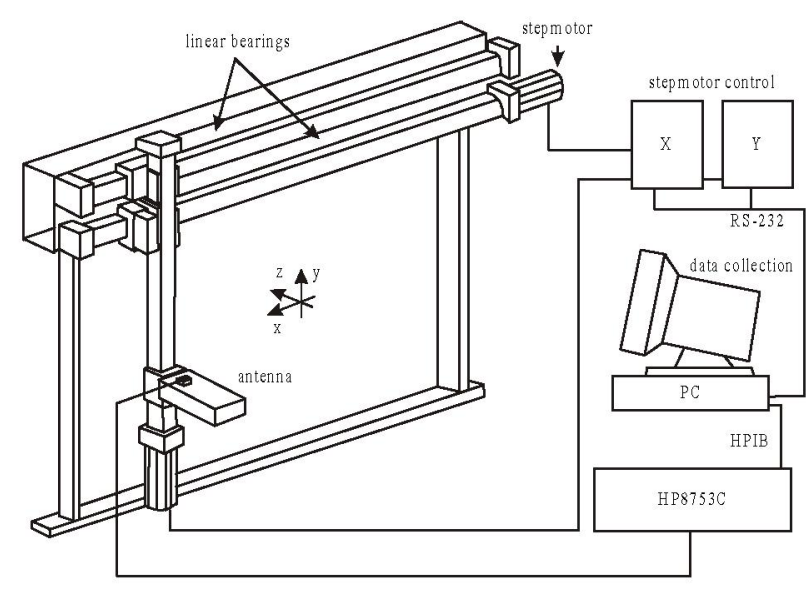

Figure 5. Outline of the indoor measurement facilities. The position of the antenna is controlled in the $\mathrm{x}$ and $\mathrm{y}$-direction by the $\mathrm{PC}$ via the step motors.

measured polarisation ellipse the axial ratio $(A R)$ is found to be less than $3.3 \mathrm{~dB}$ in the frequency range from $0.8-2.6 \mathrm{GHz}$. The antenna is designed to meet conditions where circular polarisation is required. A commonly used criterion is that the axial ratio should be less than $6 \mathrm{~dB}$ [13]. The presented spiral antenna satisfies this criterion.

\section{THE STEPPED FREQUENCY RADAR}

The experiments are based on the stepped frequency radar approach [15]. A schematic outline of the used system is shown in Figure 5.

The measurement system consists of linear bearings where the antenna is mounted. The antenna can be moved in the $\mathrm{x}$ and $\mathrm{y}$-directions in steps down to $10 \mathrm{~mm}$. The antenna position is controlled by a PC using stepmotors. The antenna is connected via a $10 \mathrm{~m}$ long coaxial cable to an HP8753C network analyser that is set up to measure the amplitude and phase of the reflection coefficient.

The designed wideband spiral antenna including feed network is used both as the transmitting and the receiving antenna, i.e., monostatic operation. The HP8753C network analyser was setup for automatic data collection of the measured amplitude and phase of the reflection coefficient. The collected data at each measurement point consist of reflection coefficient measurement at $\mathrm{N}$ frequencies evenly spaced over a selected frequency range, i.e., 301 frequencies in the range of $0.4-3.8 \mathrm{GHz}$ resulting in a step size of 10 MHz. Figure 6 (a) shows the $x, y$ coordinates for the each measurement set-up. In the experiment the antenna were stepped $10 \mathrm{~mm}$ in both $\mathrm{x}$ and $\mathrm{y}$-directions. The size of the scan area is $500 \times 500 \mathrm{~mm}$.

\section{TEST-FIELD MEASUREMENTS}

The presented data were collected at a large-scale indoor test facility at the Swedish Defence Research establishment (FOA). 


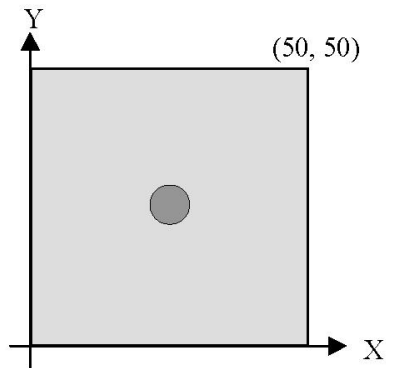

$(0,0)$

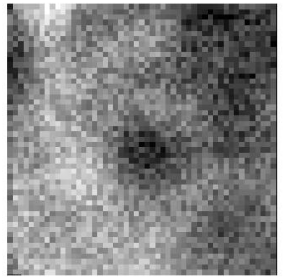

(b)
Figure 6. The black mark indicates the non-metallic M56 dummy AP-mine filled with beeswax (a). The corner coordinates indicate the number of the measurement point. (b) Image generated by using the raw probe data without any signal processing

Measurements have been performed on moist soil containing a buried, non-metallic dummy M-56 APmine where the explosive was substituted with beeswax. The object has an irregular shape with a diameter of $54 \mathrm{~mm}$ and a height of $40 \mathrm{~mm}$; the object is placed 50 mm below the surface.

The spiral antenna is elevated $175 \mathrm{~mm}$ above the ground thus operating both in the near field and in the far field, dependant on the frequency of operation.

Successfully detection of the plastic AP-mine has been obtained as shown in Figure 6 (b), however the object is not easily identifiable.

It is important to notice that the imaged picture, that is shown in Figure 6 (b) is generated only using the raw measurement data. It is therefore expected that improved detection is possible by applying some advanced signal processing, e.g., Principal Component Analysis [16].

Preliminary study of the measured data has been made. The principle of using a spiral antenna as an antenna in a monostatic radar seems reasonable.

One major problem in the used setup is the $10 \mathrm{~m}$ long coaxial cable, which introduces a two way loss of $25 \mathrm{~dB}$ for frequencies above $3.0 \mathrm{GHz}$. Improved detection could be obtained by reducing the length of the cable.

\section{CONCLUSIONS}

A spiral antenna is designed and prototyped for the FR-4 substrate. A balun is designed and prototyped for the Duriod substrate. The electromagnetic simulation program, IE3D, has been used to simulate the performance of the spiral antenna and the balun.

The measured return loss for the fabricated spiral antenna including the balun is better than $10 \mathrm{~dB}$ over a 9 to 1 bandwidth from 0.4 to $3.8 \mathrm{GHz}$.

Anechoic chamber measurements from $0.8-2.6 \mathrm{GHz}$ are made showing an axial ratio of less than $3.3 \mathrm{~dB}$ and a directivity in the range between 2.7 and $6.6 \mathrm{~dB}$.

A monostatic stepped-frequency radar approach has been proposed to detect small non-metallic buried APmines using a broadband spiral antenna.

An M-56 AP-mine with a diameter of $54 \mathrm{~mm}$ and a height of $40 \mathrm{~mm}$, only, has been successfully detected.
So far, promising results have been obtained using a SF-GPR. However, detecting small non-metallic mines is still of major concern. The SF-GPR signal from plastic mines is in general very small, due to the fact that plastic has similar electromagnetic properties as ordinary types of soil.

The constructed uniplanar spiral antenna and the balun is very well suited to be used in a SF-GPR for humanitarian demining due to the very wide bandwidth, circular polarisation, relative small size, and being uniplanar.

\section{REFERENCES}

[1] Bottigliero, I., "120 million landmines deployed worldwide: Fact or Fiction?", ISBN 085052731 7, UK, 2000.

[2] Iizuka, K., and Freundorfer, A., P., "Detection of nonmetallic buried objects by a step frequency radar," Proc. IEEE, vol. 71, pp. 276-279, Feb. 1983.

[3] Thaysen, J., "Broadband antennas", Department of Applied Electronics, Techn. Univ. of Denmark, in Danish, Jul. 1999.

[4] Dyson, J. D., "The unidirectional equiangular spiral antenna", IRE Trans. on antennas and propagat., pp. 329334,1959 .

[5] Dyson, J. D., "The equiangular spiral antenna", IRE Trans. on antennas and propagat., pp. 181-187, 1959.

[6] Thaysen, J., Jakobsen, K. B., and Appel-Hansen, J., "Numerical and experimental investigation of a coplanar waveguide fed spiral antenna", IEEE $24^{\text {th }}$ QMW Antenna Symposium, pp. 13-16, 2000.

[7] "IE3D User's Manual, Release 6", Zeland Software, Inc. Fremont, CA, 1999

[8] Tilley, K., Wu, X.D. and Chang, K., "Coplanar waveguide fed coplanar strip dipole antenna", Electronic Letter, Vol. 30, pp. 176-177, 1994

[9] Li, M-Y., Tilley, K., McCleary, J. and Chang, K.: "Broadband coplanar waveguide-coplanar strip-fed spiral antenna", Electron. Lett., Vol. 31, pp. 4-5, 1995.

[10] Thaysen, J., Jakobsen, K. B., and Appel-Hansen, J., "Characterisation and optimisation of a coplanar waveguide fed logarithmic spiral antenna", Accepted IEEE AP-S Conference on Antennas and Propagation for Wireless Communication, Waltham, USA, Nov. 2000.

[11] Thaysen, J., Jakobsen, K. B., and Appel-Hansen, J., "A wideband balun - how does it work?", Submitted, Jul. 2000.

[12] Thaysen, J., Jakobsen, K. B., and Appel-Hansen, J., "How a logarithmic spiral antenna radiates", Submitted, July 2000.

[13] Corzine, R. G. and Mosko, J. A., "Four-arm spiral antennas", Artech House, 1990

[14] Appel-Hansen, J., Thaysen, J., Jakobsen, K. B. "The use of SNATF for making simple far-field antenna measurements," Department of Electromagnetic Systems, Techn. Univ. of Denmark, IR 758, June 2000.

[15] Jakobsen, K. B., Sørensen, H. B. D., and Nymann, O., "Stepped-frequency ground-penetrating radar for detection of small non-metallic buried objects", SPIE's 11th Annual International Symposium, Vol. 3079, pp. 538-542, Orlando, Florida, USA, Apr. 1997.

[16] Karlsen, B., Larsen, J., Jakobsen, K., B., Sørensen, H. B. D. and Abrahamson, S., "Antenna characteristics and airground interface deembedding methods for steppedfrequency ground penetration radar measurements" SPIE's 14th Annual International Symposium, Orlando, Florida, USA, Apr. 2000. 